\title{
Management of Postoperative Ventriculoperitoneal Shunt Complications in Pediatric Patients
}

\author{
Abd Elkafy Sharaf Eldin Ebrahim, Usama Mohamed El Shokhaiby, Ahmed Aly Alkholy \\ Department of Neurosurgery, Faculty of Medicine, Al-Azhar University, Cairo \\ Corresponding author: Ahmed Aly Alkholy, Mobile: 01111819719, email: ahmad.aly.alkholy@gmail.com
}

\begin{abstract}
Background: Postoperative ventriculoperitoneal (VP) shunt complications in pediatric patients involves impaired absorption of CSF from the subarachnoid space to the venous circulation via the arachnoid villi. It also involves obstruction in flow of CSF from the ventricles to the subarachnoid space. Objective: To assess the proper management of postoperative shunt complications. Patients and Methods: Retrospective study conducted in the Neurosurgery Department of Al-Azhar University Hospitals and El-Sahel Teaching Hospital. Pediatric patients from both genders including infants and pediatric patients till 12 years old who were having postoperative ventriculoperitoneal shunt complications were assessed clinically and radiographically for the best management that include either surgical or medical ones or both .Results: The management of postoperative VP shunt malfunction is essential shunt revision of either proximal or distal catheters or the whole system if shunt disintegration is suspected. The most common organisms in shunt infection were gram positive organisms (coagulase negative staph. and staph. aureus). Conclusion: The most effective management plan is shunt revision. To prevent VP shunt malfunction, we have to make sure of intraoperative closed, sterile and functioning shunt system.
\end{abstract}

Keywords: Cerebral spinal fluid, ventriculoperitoneal shunt, computed tomography.

\section{INTRODUCTION}

Hydrocephalus is defined as dilatation of the ventricular system of brain resulting from an imbalance between the production and absorption of cerebral spinal fluid (CSF). This imbalance results in an increased volume of CSF, dilation of the ventricular system, and often increased intracranial pressure (ICP). Hydrocephalus onset can be acute and occur over hours or days. It may also be chronic and occur over months or years. Hydrocephalus can occur as an isolated condition or one associated with numerous other neurological conditions and diseases. Hydrocephalus can then be classified as either communicating or non-communicating (l). Postoperative ventriculoperitoneal (VP) shunt complications in pediatric patients involves impaired absorption of CSF from the subarachnoid space to the venous circulation via the arachnoid villi. It also involves obstruction in flow of CSF from the ventricles to the subarachnoid space ${ }^{(I)}$.

Patients presented with hydrocephalus are treated with CSF shunt insertion. CSF shunt technology is one of the great advances in modern medicine. The survival rates and quality of life of patients with hydrocephalus have improved dramatically since the introduction of shunts almost 50 years ago. CSF shunt infection is one of the serious complications of shunt insertion that have decreased over the years as smaller devices with biocompatible materials have been introduced and as the surgical technique and devices used to insert a shunt have been perfected $^{(2)}$.

In infants and small children, typical symptoms such as irritability and vomiting occur with many other medical problems. Imaging studies are indicated when these symptoms occur in the context of findings suggestive of an intracranial process (e.g. lethargy, seizures and increasing head circumference). The initial diagnostic study is often a plain computed tomography (CT) scan of the head. It clearly demonstrates the ventricular size and usually identifies whether a mass lesion is present or not ${ }^{(3)}$.

\section{AIM OF THE WORK}

This study was conducted to assess the proper management of postoperative shunt complications.

\section{PATIENTS AND METHODS}

Retrospective study conducted in the Neurosurgery Department of Al-Azhar University Hospitals and El-Sahel Teaching Hospital.

Patients' clinical and imaging progress were reviewed to assess the postoperative shunt complications with trial of available methods to prevent these complications.

\section{Ethical approval}

This study was approved from the Ethical Committee Faculty of Medicine Al-Azhar University after obtaining consents from parents

Inclusion criteria: Cases with hydrocephalus treated by ventriculoperitoneal shunt with postoperative complications (proximal obstruction distal end failure - infection) within one year. Both genders with age group including infants and pediatric patients till 12 years old.

Exclusion criteria: Postoperative complications due to other CSF diversionary devices (Ventriculoatrial, ventriculopleural $\quad \ldots \quad$ etc.). Postoperative complications with VP shunt in adults.

Diagnosis: Patients were diagnosed by clinical picture including medical and surgical ones.

Evaluation of cases: 
Clinically: All pediatric patients less than 12 years old presented with postoperative VP shunt complications were assessed clinically with proper history taking and asking about the presence of (fever, vomiting, decreased feeding, seizures, etc...) and proper neurological examination.

Laboratory tests: Series of CSF samples taken from the reservoir of the shunt and examined for cell count including TLC (total leukocyte count)with differential count, CSF chemical analysis including protein, glucose and chloride, CSF culture and sensitivity (C and S), C.B.C (complete blood count), ESR (erythrocyte sedimentation rate), CRP (c- reactive protein).

Radiological tests: In the form of e.g. (CT brain, $\mathrm{x}$-ray to the entire shunt system, abdominal ultrasound, etc...) were done for suspected patients of postoperative shunt infection. (Contrast brain imaging including MRI when applicable)

Follow up: All the patients in this study were assessed clinically, laboratory and radiologically after discharge from the hospital at 10 days and 3 months interval in the outpatient clinic. All the collected data were registered.

Patients were arranged according to different management plans as following:

For management plan of infected cases, patients were arranged into two groups: $\operatorname{Group}(A)$ : Open head patients (< 18 months of age): Management plan consisted of one of the following methods: Medical treatment tried in patients with CSF TLC with differential < $300 \mathrm{cell} / \mathrm{cmm}$, abnormal CSF glucose, protein and chloride, with or without positive CSF C and S. Intravenous antibiotics from 10 - 14 days and CSF infection evaluated by serial CSF samples taken from the reservoir was examined for cytological exams till CSF TLC with differential $<5 \mathrm{cell} / \mathrm{cmm}$, and normal labs for 3 consecutive results. If CSF TLC with differential (300 $1000 \mathrm{cell} / \mathrm{cmm}$ ) and abnormal CSF protein, glucose, chloride, this was managed by surgical removal of infected shunt and repeated ventricular taps were done at regular intervals. Every three days, CSF samples taken for CSF TLC with differential, CSF (protein, glucose, chloride) and labs. Intravenous antibiotics started empirically and modified according to CSF C and S for about 14 days. The effect of antibiotics in eradication of infection followed by serial CSF cytological exams, labs and improvement of clinical presentation. Once CSF TLC with differential $<5 \mathrm{cell} / \mathrm{cmm}$, and normal labs for 3 consecutive results, new CSF was shunt implanted. If CSF TLC with differential $>1000 \mathrm{cell} / \mathrm{cmm}$ and CSF C and $\mathrm{S}$ showed resistant to antibiotic therapy; the patients were treated with removal of infected CSF shunt and external ventricular drain (EVD) placed or externalization of the shunt. Every three days, CSF samples were taken for CSF cytological exam. Intravenous antibiotics started empirically and modified according to CSF C and S. Intraventricular antibiotics were injected via EVD. The effect of antibiotics in eradication of infection was followed by serials of CSF cytological exams, CSF, labs and improvement of clinical presentation. Once CSF TLC with differential $<5$ cell/cmm and normal labs; EVD was removed and new CSF shunt was inserted.

Group (B): Closed head patients (>18 months 12 years old): Management consisted of one of the following methods: Medical treatment was tried in patients with CSF TLC with differential $<300 \mathrm{cell} / \mathrm{cmm}$ with or without positive CSF C and S. Intravenous antibiotics for 10 - 14 days and CSF infection evaluated by serial CSF samples taken from the reservoir was examined for cytological exams with culture and sensitivity (C and S) till CSF TLC with differential $<5$ cell $/ \mathrm{cmm}$ and normal labs for 3 consecutive results. If CSF TLC with differential $>300 \mathrm{cell} / \mathrm{cmm}$ and CSF C and $\mathrm{S}$ showed resistant to antibiotic therapy; the patients were treated with removal of infected CSF shunt and external ventricular drain (EVD) placed or externalization of the shunt. Every three days, CSF samples were taken for CSF cytological exam. Intravenous antibiotics started empirically and was modified according to CSF C and S. Intraventricular antibiotics were injected via EVD. The effect of antibiotics in eradication of infection was followed by serials of CSF cytological exams, CSF C and S, labs and improvement of clinical presentation. Once CSF TLC with differential $<5$ cell//cmm and normal labs. EVD was removed and new CSF shunt was inserted.

For management plan of patients with shunt obstructed cases: In patients with postoperative shunt obstruction and the diagnosis was established by means of examination in the form of delayed refilling in case of proximal obstruction and hardening of the valve in case of distal obstruction as well as radiological investigations (CT brain, pelvi-abdominal U/S, plain x-ray films); we did shunt revision with possibility of changing the ventricular catheter, peritoneal catheter, or the whole system.

For management plan of shunt protrusion through anal orifice: The shunt tube was disconnected at the abdominal wall and removed through the orifice via endoscopy or colonoscopy. The distal end was not pulled back through the peritoneal cavity if at all possible, in order to prevent contamination. The distal catheter was exteriorized; the catheter was cut and connected to EVD. Serial abdominal examination and CSF samples were taken and after they all became free from either infection or inflammation re-shunting took place.

For management plan of wound site infection or shunt exposure: In these patients we first took CSF sample to determine whether infection reached shunt hardware or not beside samples from wound itself for $\mathrm{C}$ and $\mathrm{S}$ examination too. Empirical antibiotics started soon, then if a) CSF sample was clean from infection $2^{\text {ry }}$ wound closure was done without revision of shunt. b) CSF sample proved infection, intravenous antibiotics for $10-14$ days and 
CSF infection evaluated by serial CSF samples taken from the reservoir were examined for cytological exams with culture and sensitivity ( $\mathrm{C}$ and $\mathrm{S}$ ) till CSF TLC with differential $<5$ cell $/ \mathrm{cmm}$ and normal labs for 3 consecutive results then $2^{\text {ry }}$ closure was done concomitant with re shunting.

RESULTS

Table (1): Demographic data

\begin{tabular}{|l|l|c|c|}
\hline \multicolumn{2}{|c|}{} & No. & \multicolumn{1}{|c|}{$\%$} \\
\hline \multirow{2}{*}{ Sex } & Female & 12 & $40.0 \%$ \\
\cline { 2 - 4 } & Male & 18 & $60.0 \%$ \\
\hline \multirow{3}{*}{ Age (months) } & From 1 to 6 months & 10 & $33.3 \%$ \\
\cline { 2 - 4 } & From 7 to 12 months & 8 & $26.70 \%$ \\
\cline { 2 - 4 } & From 13 to 18 months & 3 & $10.00 \%$ \\
\cline { 2 - 4 } & From 19 to 24 months patients & 1 & $3.30 \%$ \\
\cline { 2 - 4 } & From 25 to 144 months & 8 & $26.7 \%$ \\
\hline
\end{tabular}

Table (2): Clinical picture on admission

\begin{tabular}{|c|c|c|c|}
\hline & & No & $\%$ \\
\hline \multirow{10}{*}{ Clinical picture on admission } & Fever & 14 & $46.7 \%$ \\
\hline & Vomiting & 13 & $43.3 \%$ \\
\hline & Increased head circumference & 7 & $23.3 \%$ \\
\hline & wound infection and Exposed reservoir & 10 & $33.3 \%$ \\
\hline & Abnormality of ant. fontanel & 7 & $23.3 \%$ \\
\hline & Poor feeding and Irritability & 5 & $16.7 \%$ \\
\hline & Protrusion of distal End through anus & 1 & $3.3 \%$ \\
\hline & DCL & 2 & $6.7 \%$ \\
\hline & Sub galial collection & 1 & $3.3 \%$ \\
\hline & Repeated fits & 1 & $3.3 \%$ \\
\hline
\end{tabular}

Table (3): Valve condition

\begin{tabular}{|l|l|c|c|}
\hline \multicolumn{2}{|c|}{} & No & \% \\
\hline \multirow{3}{*}{ Valve condition } & Hardening of valve & 6 & $20.0 \%$ \\
\cline { 2 - 4 } & Functioning & 9 & $30.0 \%$ \\
\cline { 2 - 4 } & Malfunctioning & 16 & $53.3 \%$ \\
\hline
\end{tabular}

Table (4): Laboratory findings in CSF analysis for protein and glucose:

\begin{tabular}{|l|c|c|}
\hline & No & $\%$ \\
\hline High CSF total protein & 13 & $43.3 \%$ \\
\hline Low CSF glucose & 15 & $50.0 \%$ \\
\hline
\end{tabular}

Table (5): CSF culture and sensitivity results:

\begin{tabular}{|l|c|c|}
\hline & No & \% \\
\hline$\quad$ Positive CSF & $\mathbf{7}$ & $\mathbf{2 3 . 3 \%}$ \\
\hline - $\quad$ Staph aureus & 2 & $28.6 \%$ \\
\hline - $\quad$ Klebsiella spp. & 1 & $14.3 \%$ \\
\hline - $\quad$ Pseudomonas spp. & 1 & $14.3 \%$ \\
\hline - $\quad$ E. coli & 1 & $14.3 \%$ \\
\hline - Staph epiderminds & 2 & $28.6 \%$ \\
\hline$\quad$ Negative CSF & $\mathbf{2 3}$ & $\mathbf{7 6 . 7 \%}$ \\
\hline
\end{tabular}

Table (6): Percentage of open and closed head patients

Open head

Closed head

\begin{tabular}{|c|c|}
\hline No. & \% \\
\hline 21 & $70.0 \%$ \\
\hline 9 & $30.0 \%$ \\
\hline
\end{tabular}


Table (7): Indications for initial VP shunt insertion

\begin{tabular}{|c|l|c|c|}
\hline \multicolumn{2}{|c|}{} & No & \% \\
\hline \multirow{3}{*}{ Type pathology } & Congenital hydrocephalus & 23 & $76.7 \%$ \\
\cline { 2 - 4 } & Post traumatic hydrocephalus & 4 & $13.3 \%$ \\
\cline { 2 - 4 } & Meningocele repair & 2 & $6.7 \%$ \\
\cline { 2 - 4 } & Post menigitic hydrocephalus & 1 & $3.3 \%$ \\
\hline
\end{tabular}

Table (8): Type of postoperative complication

\begin{tabular}{|c|c|c|c|}
\hline & & No & $\%$ \\
\hline \multirow{9}{*}{ Type of postoperative complication } & Distal end obstruction & 4 & $13.3 \%$ \\
\hline & Exposed shunt & 5 & $16.3 \%$ \\
\hline & Malfunctioning shunt & 1 & $3.3 \%$ \\
\hline & Over drainage & 1 & $3.3 \%$ \\
\hline & Postoperative shunt infection & 6 & $20.0 \%$ \\
\hline & Postoperative wound infection & 4 & $13.3 \%$ \\
\hline & Proximal end malposition & 1 & $3.3 \%$ \\
\hline & Proximal end obstruction & 7 & $23.3 \%$ \\
\hline & Sub galial collection & 1 & $3.3 \%$ \\
\hline
\end{tabular}

Table (9): Management plan

\begin{tabular}{|l|l|c|c|}
\hline \multicolumn{2}{|c|}{} & No & \% \\
\hline \multirow{4}{*}{ Management plan } & Shunt removal & 6 & $20 \%$ \\
\cline { 2 - 4 } & EVD insertion & 4 & $13.3 \%$ \\
\cline { 2 - 4 } & Shunt revision & 12 & $40 \%$ \\
\cline { 2 - 4 } & Wound debridement and closure & 6 & $20 \%$ \\
\cline { 2 - 4 } & Distal end revision & 1 & $3.3 \%$ \\
\cline { 2 - 4 } & Antibiotics alone & 1 & $3.3 \%$ \\
\hline
\end{tabular}

Table (10): Survival rate in the study:

\begin{tabular}{|c|l|c|c|}
\hline \multicolumn{2}{|c|}{ Survival rate } & No & \% \\
\cline { 2 - 4 } & Died & 29 & $96.7 \%$ \\
\hline
\end{tabular}

\section{CASE}

4 years old, female patient, presented with post traumatic hydrocephalus was operated upon with V-P shunt insertion and after one months of surgery, the patient presented with fever, malaise, proximal wound infection over the reservoir suspected shunt infection.

By examination, the valve was pumping and the shunt was functioning.

Radiological test: CT Brain hydrocephalic changes controlled by VP shunt, ventricular catheter in place.

Laboratory tests in the form of CSF sample was taken for cytological examination, Culture and sensitivity, C.T brain scan and results were as follows:
Cytology exam results:

Table (11): CSF Cytology examination results:

\begin{tabular}{|l|l|}
\hline Color & Clear \\
\hline Direct smear & $260 \mathrm{cell} / \mathrm{cmm}$ \\
\hline TLC count: & \\
\hline Leishman & $70 \%$ \\
\hline Stain & $30 \%$ \\
PMNLs & \\
\hline Lymphocytes & \\
\hline
\end{tabular}




\section{Culture and sensitivity result:}

- Colony count $>15 /$ catheter segment

- Organism isolated: no growth

\section{Management strategy:}

The patient was treated with antibiotics for 14 days by intravenous vancomycin and ceftriaxone. A series of CSF cytology exams to assess the efficacy of treatment as follows:

Table (12): A series of CSF cytology examination and $\mathrm{C}$ and $\mathrm{S}$ results:

\begin{tabular}{|l|lr|l|}
\hline & \multicolumn{2}{|c|}{$\begin{array}{c}\text { cLC } \\
\text { count }\end{array}$} & \multicolumn{1}{|c|}{$\begin{array}{l}\text { Isolated } \\
\text { organisms }\end{array}$} \\
\hline $\begin{array}{l}\text { At start of } \\
\text { antibiotics }\end{array}$ & $\begin{array}{l}260 \quad \text { cell/ } \\
\mathrm{cmm}\end{array}$ & No growth \\
\hline $\begin{array}{l}\text { After } \mathbf{5} \\
\text { days }\end{array}$ & $\begin{array}{l}80 \quad \text { cell } \\
/ \mathrm{cmm}\end{array}$ & No growth \\
\hline After 10 days & $\begin{array}{l}<5 \quad \text { cell } \\
/ \mathrm{cmm}\end{array}$ & No growth \\
\hline
\end{tabular}

After 14 days of antibiotics and CSF TLC with differential $<5 \mathrm{cell} / \mathrm{cmm}$ and normal CSF glucose, protein, chloride and normal labs for consecutive 3 results, proximal wound healed and there was improvement in the general condition then the patient was discharged home without shunt revision

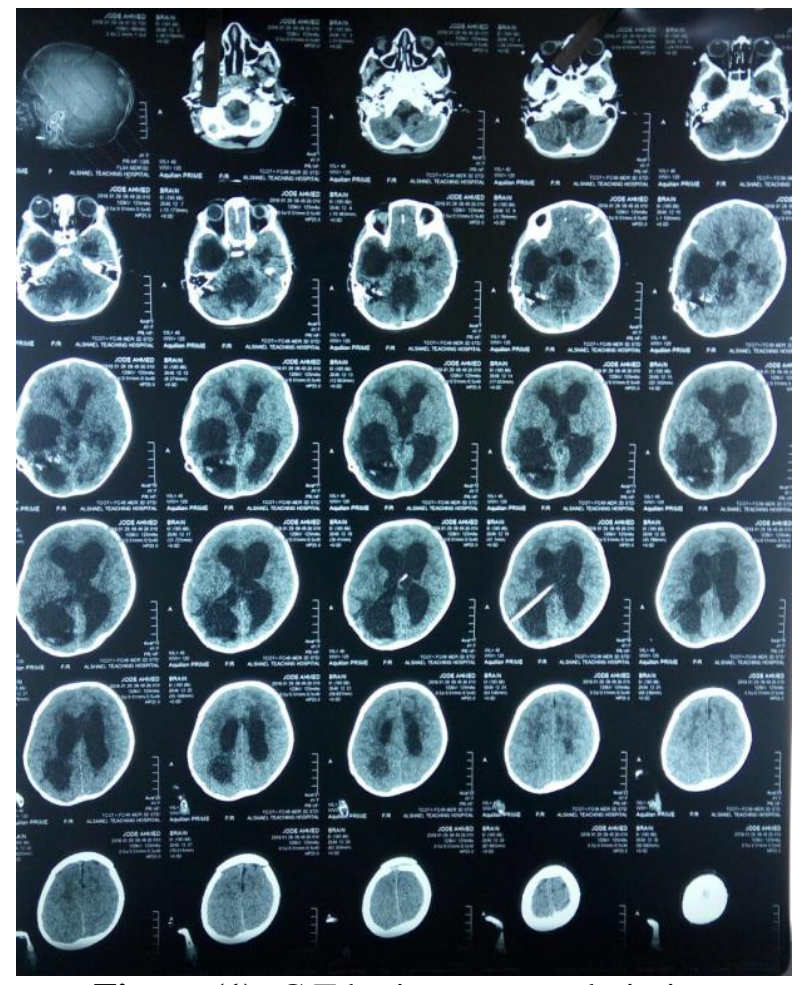

Figure (1): C.T brain scan on admission

\section{Follow up:}

At 15 days of discharge: no clinical manifestations of shunt infection, shunt was pumping, clean wound.
This study was conducted on 30 pediatric patients, all of them known to be hydrocephalic and were operated upon by VP shunt insertion. 10 patients developed postoperative shunt obstruction (proximal obstruction and distal end failure) and 6 patients developed postoperative shunt infection with variable others.

In our study, the most common age distribution of patients with shunt complications was between 1-6 months of age (33.3\%) and percentage of males were $(60 \%)$ and females were $(40 \%)$. This comes in comparable with the study of OrregoGonzález et al. ${ }^{(4)}$, who did his study on 83 patients and mentioned that the most common age distribution was less than one month $(41 \%)$ and male patients were predominant in his study reaching $(50.6 \%)$ while female patients were $(49.4 \%)$

The clinical findings of patients with VP shunt complications in our study varied according to the patient's age, virulence of the microorganism and other variables.

In our study, the most presenting symptom was fever in fourteen patients out of thirty, representing $(46.7 \%)$, while vomiting came the second most presenting symptoms in thirteen patients of thirty, representing (43.3\%). Gündeşlioğlu et al ${ }^{(5)}$ In their study mentioned that the most common complaint was nausea and vomiting $(66.7 \%)$ followed by loss of appetite $(57.6 \%)$ then fever $(51.5 \%)$.

In our study the most common postoperative complication was shunt obstruction reaching (36.5\%) in which proximal end obstruction was in seven patients $(23.3 \%)$ and distal end obstruction was in four patients (13.3\%). The second most common complications collectively was in ten patients (33.3\%) was infection in which six patients of them were having postoperative shunt infection (19.9\%), while the rest four patients were having postoperative wound infection (13.3\%). Orrego- González et al. ${ }^{(4)}$ reported that the leading cause of shunt failure in his study was obstruction of the shunt $(61.9 \%)$, followed by infection $(38.1 \%)$.

From the obstruction cases within the current study (eleven cases), proximal end obstruction reached $(63.6 \%)$ while distal end obstruction was (36.4\%). a study of Hoppe-Hirsch ${ }^{(6)}$ mentioned that in all of his obstructed case, proximal end obstruction was $(70 \%)$ while distal end obstruction was (20\%) and other portions of the shunt was (10\%).

Stone et al. ${ }^{(7)}$ in their study on 64 patients mentioned that, the catheter clogged category were $(52 \%)$ of cases, including proximal obstruction $(27 \%)$, distal obstruction $(15 \%)$, valve $(8 \%)$, or complete occlusion (2\%).

The management plan in the thirty patients of this study was different according to varying etiology, patient age, CSF condition, etc.... Shunt revision reached the most common management strategy that was done in thirteen patient $(40 \%)$ then shunt 
removal, intravenous antibiotic and new shunt replacement in sex patient $(20 \%)$ while EVD insertion and intravenous antibiotics, with intraventricular antibiotics was used in 4 patients $(13.3 \%)$, wound debridement and closure was (20\%). Medical treatment was used alone in one patient $(3.3 \%)$ that comes in same percentage as distal end revision too $(3.3 \%)$.

Removal of shunt hardware as a host of infection in case of CSF involvement and drainage by EVD showed a success rate varying between 60 and $85 \%{ }^{(8,9)}$. Tubbs et al. ${ }^{(10)}$, Fulmer et al. ${ }^{(11)}$, reported it as 84 and 75 respectively. In the current study we had a success rate of $66.6 \%$ (4 patients of 6 ).

The importance of laboratory results in decision making and follow up of complicated VP shunt cases is crucial. In our study we found that CSF analysis for protein was high in thirteen patients of thirty, representing (43.3\%) and CSF analysis for glucose was low in fifteen patients of thirty, representing (50\%). Orrego- González et al. (4) reported that CSF protein levels were high in $(36.3 \%)$ while CSF glucose levels were low in (23.2\%)

CSF culture and sensitivity examination plays a major role in the plan of management strategy of postoperative VP shunt complications in which it decides if there is CSF infection or not. We found that CSF infection with a need for shunt hardware removal and insertion of EVD were positive in seven patients $(23.3 \%)$ and negative in twenty three patients (76.7 $\%)$, both groups needed proper antibiotics and care of wound.

In the study of Gündeşlioğlu et al. ${ }^{(5)}$ they found that the active microorganism was detected in brain spinal fluid of $(69.6 \%)$ of the patients and the most common microorganism was $\mathrm{S}$. epidermidis $(82.6 \%)$.

The most common organisms in our study were coagulase negative staph; aures and epidemidis representing $28.6 \%$ respectively.

McGirt et $\boldsymbol{a l} .^{(12)}$ reported in their study that the most common organisms were coagulase-negative staphylococcus species in $(53 \%), \mathrm{S}$. aureus in 24 cases (26\%), gram-negative rods in 8 cases (9\%) and E. faecalis in 4 cases $(4 \%)$.

The exact duration of antibiotic therapy required to prevent re-infection remains unknown, although most surgeons require at least 5 to 10 days of treatment prior to re-internalization of the shunt. During external drainage, CSF cultures can be sent regularly to establish when CSF sterility is achieved. Fulmer et al. express the usage of antibiotics 5 to 10 days and two weeks in case of EVD ${ }^{(11)}$. In our study we expressed the antibiotic usage for 5 to 10 days as average and 10 to 14 days with EVD.

The most common presenting condition of the valve in this study was shunt malfunction in sixteen patients of thirty representing $(53.3 \%)$.
The technique of valve compression as a clinical sign of shunt complication seems to be nondependable because in our thirty complicated cases we found that nine patients representing $(30 \%)$ of cases were having clinically functioning valve regardless they were already complicated; however it seems to be a sign of shunt failure as in the study of Di Rocco et al. (13) who found that the incidence of mechanical complications of the shunt were high $(17.8 \%)$

Most patients of CSF shunt complication were open head group (< 18 months) $(70 \%)$ while closed head group ( $>18$ months -12 years old) was $(30 \%)$.

The most common indication for initial VP shunt insertion and presented later on with shunt problems was congenital hydrocephalus operated upon with VP shunt insertion; reaching twenty-three patients of thirty $(76.7 \%)$, while the second most common reason was patients with post-traumatic hydrocephalus operated upon with VP shunt insertion; which was in four patients out of thirty $(13.3 \%)$

In the study of Orrego-González et al. ${ }^{(4)}$ he found that the most common indication for initial VP shunt insertion was brain tumor $(26.5 \%)$ while the second most common indication was intraventricular hemorrhage of the premature (19.3\%). This is possibly due to the differences in ages of the study population.

Based on our study and findings, our recommendation for the management of VP shunt complications in pediatric patients is proper preparation and good assessment of clinical condition of the patient for proper management strategy. Shunt removal is not a must in all infected VP shunt cases. However proper antibiotic treatment seems to be enough.

The proper detection of the area of malfunction is a necessary point for those of malfunction.

\section{CONCLUSION}

The most effective management plan for postoperative ventriculoperitoneal shunt complications in pediatric patients is shunt revision.

\section{REFERENCES}

1. Drake J and Abou-Hamden A (2011): Ch 27 Hydrocephalus and arachnoid cysts. In: Swaiman's pediatric neurology. 5 th ed. Saunders.

2. Sacar S, Turgut H, Toprak S et al. (2006): A retrospective study of central nervous system shunt infections diagnosed in a university hospital during a 4year period. BMC Infect Dis., 8;6:43.

3. Drake JM, Kestle JR, Milner $R$ et al. (1998): Randomized trial of cerebrospinal fluid shunt valve design in pediatric hydrocephalus. Neurosurgery, 43(2):294-303.

4. Orrego-González E, Enriquez-Marulanda A, Ravindran Ket al. (2019). Factors Associated with Ventriculoperitoneal Shunt Failures in the First 30 Postoperative Days in Pediatric Patients. World neurosurgery, 124: e517-e526. 
5. Gündeşlioğlu ÖÖ, Haytoğlu Z, Özsoy KM et al. (2018): Ventriculoperitoneal Shunt Infections in Children: Demographical, Clinical Findings and Evaluation of Thrombocyte Parameters. Cocuk Enfeksiyon Dergisi., 12(2): E63-E69.

6. Hoppe-Hirsch E, Laroussinie F, Brunet L et al. (1998): Late outcome of the surgical treatment of hydrocephalus. Child's nervous system, 14(3):97-9.

7. Stone JJ, Walker CT, Jacobson M et al. (2013): Revision rate of pediatric ventriculoperitoneal shunts after 15 years. Journal of Neurosurgery: Pediatrics, 11(1): 15-19.

8. Koksal V and Oktem S (2010): Ventriculoperitoneal shunt procedure

and its long-term outcomes in infants with postoperative hydrocephalus. Childs Nerv Syst., 26: 1505-1515.

9. Shooman D, Portess H, Sparrow O (2009): A review of the current treatment methods for posthaemorrhagic hydrocephalus of infants. Cerebrospinal fluid research, 6(1): 1.
10. Tubbs RS, Banks JT, Soleau S, Smyth MD, Wellons JC, Blount JP, Grabb PA, Oakes WJ (2005): Complications of ventriculoperitoneal shunts in infants and children. Childs Nerv Syst., 21: 48-51.

11. Fulmer BB, Grabb PA, Oakes WJ et al. (2000): Neonatal ventriculoperitoneal shunts. Neurosurgery, 47: 80-83.

12. McGirt MJ, Zaas A, Fuchs HE et al. (2003). Risk factors for pediatric ventriculoperitoneal shunt infection and predictors of infectious pathogens. Clinical infectious diseases, 36(7): 858-862.

Di Rocco C, Marchese E, Velardi F (1994): A survey of the first complication of newly implanted CSF shunt devices for the treatment of nontumoral hydrocephalus. Child's Nervous System, 10(5): 